\title{
Effects of autacoid inhibitors and of an antagonist on malaria infection in mice
}

E.O. Iwalewa ${ }^{1}$ and E.O. Agbani²

\author{
Departments of ${ }^{1}$ Pharmacology and 2 Pharmaceutics, Faculty of Pharmacy, \\ Obafemi Awolowo University, Ile-Ife, Nigeria
}

\section{Correspondence}

E.O. Iwalewa

Department of Pharmacology

Faculty of Pharmacy

Obafemi Awolowo University

Ile-Ife

Nigeria

E-mail: eoiwalewa@yahoo.com

Received June 2, 2003

Accepted May 3, 2004

\begin{abstract}
The effects of p-chlorophenylalanine, an inhibitor of serotonin synthesis, indomethacin, an inhibitor of prostaglandin synthesis, cyproheptadine, a serotonin, bradykinin and histamine antagonist, were assessed separately and in combination with chloroquine (CQ) in Vom strains of Swiss albino mice (18-22 g) of either sex infected intraperitoneally with $1 \times 10^{7}$ Plasmodium yoelii nigeriensis-induced malaria. As prophylactic, these agents reduced from $31.9 \pm 4.5$ to $16.1 \pm 8.1 \%$ the level of parasitemia relative to control but had no appreciable activity as curative agents when administered subcutaneously once daily for 4 days after $72 \mathrm{~h}$ of parasites innoculum in vivo. However, CQ alone and the combination of these agents with CQ in curative and prophylactic treatments significantly reduced (from $50.3 \pm 5.8$ to $4.9 \pm$ $0.75 \%$ ) the level of parasitemia $(\mathrm{P}<0.05)$, which was taken only once $72 \mathrm{~h}$ after the parasites innoculum. The prophylactic result was shown to produce better results than the curative treatment. The data indicate that inhibitors and an antagonist can reduce the parasitemia load (the extent of damage and the severity of infection) as well as enhance the effects of CQ when combined with it for malaria therapy. The study reveals that the production of autacoids in established infection renders autacoid inhibitors and an antagonist ineffective for radical cure in malarial mice; however, selective inhibition of local hormones implicated in the pathological manifestations of malaria infection by autacoid inhibitors and an antagonist may be a possible pathway to reduce the severity of infection and the associated tissue damage and to enhance the efficacy of available anti-malarials.
\end{abstract}

\section{Introduction}

Malaria is a major disease in tropical climates, with high mortality rates. Despite serious efforts to eradicate the disease, malaria is reemerging to take its toll among the inhabitants of tropical developing countries. According to the World Health Organization (WHO) (1), approximately 300-500 million individuals are infected with malaria, with death totals ranging from 1.5 to 3.5 million
Key words

- Autacoid inhibitors

- Autacoid antagonist

- Malaria infection

- Malarial prophylaxis

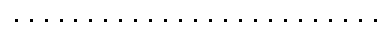

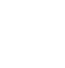


ber of autacoids (4). Autacoids, which are commonly referred to as local hormones, are pharmacologically active substances and chemical mediators of inflammatory reactions. The release of these mediators, i.e., histamine, bradykinins, 5-hydroxytryptamine (5-HT), and prostaglandins, during infection by malaria parasites has been reported to be implicated in the clinical signs and symptoms of the infection (5-7). There are, however, some agents that inhibit the synthesis or antagonize the effects of these mediators, thus preventing the occurrence of the inflammatory process. The idea that an antihistaminic drug may also be antimalarial has been proposed $(8,9)$, but these studies need to be expanded.

Thus, the objective of the present study was to examine the effects produced when local hormones are inhibited or antagonized in the prophylactic and curative treatments of malarial mice with autacoid inhibitors ( $p$ chlorophenylalanine, p-CPA, and indomethacin), with an autacoid antagonist (cyproheptadine), and with chloroquine (CQ) administered separately and in combination.

\section{Material and Methods}

\section{Animals}

Swiss albino mice (18-22 g) bred in the Animal House of the Faculty of Pharmacy, Obafemi Awolowo University, Ile-Ife, Nigeria, were used. The animals received standard food (Ladokun Feeds, Ibadan, Nigeria) and water ad libitum and were maintained under standard conditions of humidity and temperature on a 12-h light/dark cycle. The animals were acclimated for one week before being used. The "Principles of Laboratory Animal Care" (NIH, Publication No. 85-23) were followed in this study.

\section{Drugs}

p-CPA (Sigma), crystalline indomethacin (Sigma), cyproheptadine (Prodrome Química and Farmacêutica Ltda., São Paulo, SP, Brazil), and CQ sulfate (Rhone-Poulenc Rorer, Collegeville, PA, USA) were used.

\section{Parasites and inoculum preparation}

The N67 CQ-sensitive strain of $P$. yoelii nigeriensis from the Department of Pharmacology and Therapeutics, University of Ibadan, Ibadan, Nigeria, was used. A donor mouse infected with the $P$. yoelii nigeriensis strain of the rodent malaria parasite was used for inoculum preparation. The red blood cells (RBC) per unit volume were calculated from the inoculum size. The number of parasitized RBC in a volume of blood was then calculated by multiplying percent parasitemia by number of RBC. The desired volume of blood was then obtained from the donor mouse by cardiac puncture using a heparinized sterile syringe. The blood was suitably diluted with sterile normal saline so that the final inoculum $(0.2 \mathrm{ml})$ for each mouse would contain the required number of parasitized $\mathrm{RBC}\left(1 \times 10^{7} \mathrm{RBC}\right)$.

\section{Treatment protocols}

Malaria infection was established by the intraperitoneal ( $i p$ ) administration of donor blood containing $1 \times 10^{7}$ parasites. The two different methods of treating malaria infection, i.e., curative and prophylactic methods, were applied according to Ryley and Peters (10) and Peters (11), respectively.

\section{Curative method}

Forty-five mice were infected with $1 \times 10^{7}$ P. yoelii nigeriensis and held for 3 days so that the infection might be established. At the beginning of day 4, they were randomized into 9 groups of 5 mice each and treated with $0.3 \mathrm{ml}$ normal saline (the control group), $10 \mathrm{mg} / \mathrm{kg}$ pCPA, $2 \mathrm{mg} / \mathrm{kg}$ indomethacin, $10 \mathrm{mg} / \mathrm{kg}$ cyproheptadine, $5 \mathrm{mg} / \mathrm{kg} \mathrm{CQ}, \mathrm{CQ}+\mathrm{p}-\mathrm{CPA}, \mathrm{CQ}+$ indomethacin and CQ + cyproheptadine, re- 
spectively, with the ninth group receiving the combination of $\mathrm{CQ}+\mathrm{p}-\mathrm{CPA}+$ indomethacin + cyproheptadine. The drugs were administered subcutaneously daily for 4 days. Blood was obtained daily from the tail of each mouse in each group from near the end of day 3 to near the end of day 7 and used to prepare thin blood films. Percent parasitemia level was determined from these films. The animals were observed for 28 days to determine whether recovery occurred or not (10).

\section{Prophylactic method}

Nine groups of 5 mice each were treated with the same drugs and dose using the same route as in the curative method. The drugs were administered for 3 consecutive days. At the beginning of the fourth day, all animals were infected with $1 \times 10^{7} P$. yoelii nigeriensis and held for 3 days, after which blood smears were prepared from tail blood on day 7. Percent reduction in parasitemia level relative to control was calculated, and all the animals were observed for 28 days and monitored for mortality (11).

\section{Determination of parasitemia level}

Thin blood smears were prepared, air dried, fixed with methanol, air dried, stained with Giemsa, and then examined by light microscopy at $100 \mathrm{X}$ power. The mean percentage of parasitemia was calculated as follows: total number of parasitized $\mathrm{RBC} \mathrm{x}$ 100 divided by the total number of RBC.

\section{Statistical analysis}

All data generated are reported as means \pm SEM and differences between group data were determined by a modified $t$-test (12). One-way analysis of variance (ANOVA) and F-test computations were further employed to determine the significance of the variations between and within treatment groups. All $P$ values less than 0.05 were considered to be statistically significant.

\section{Results}

Figure 1 illustrates the effect of CQ, autacoid inhibitors, antagonist, and their combi-

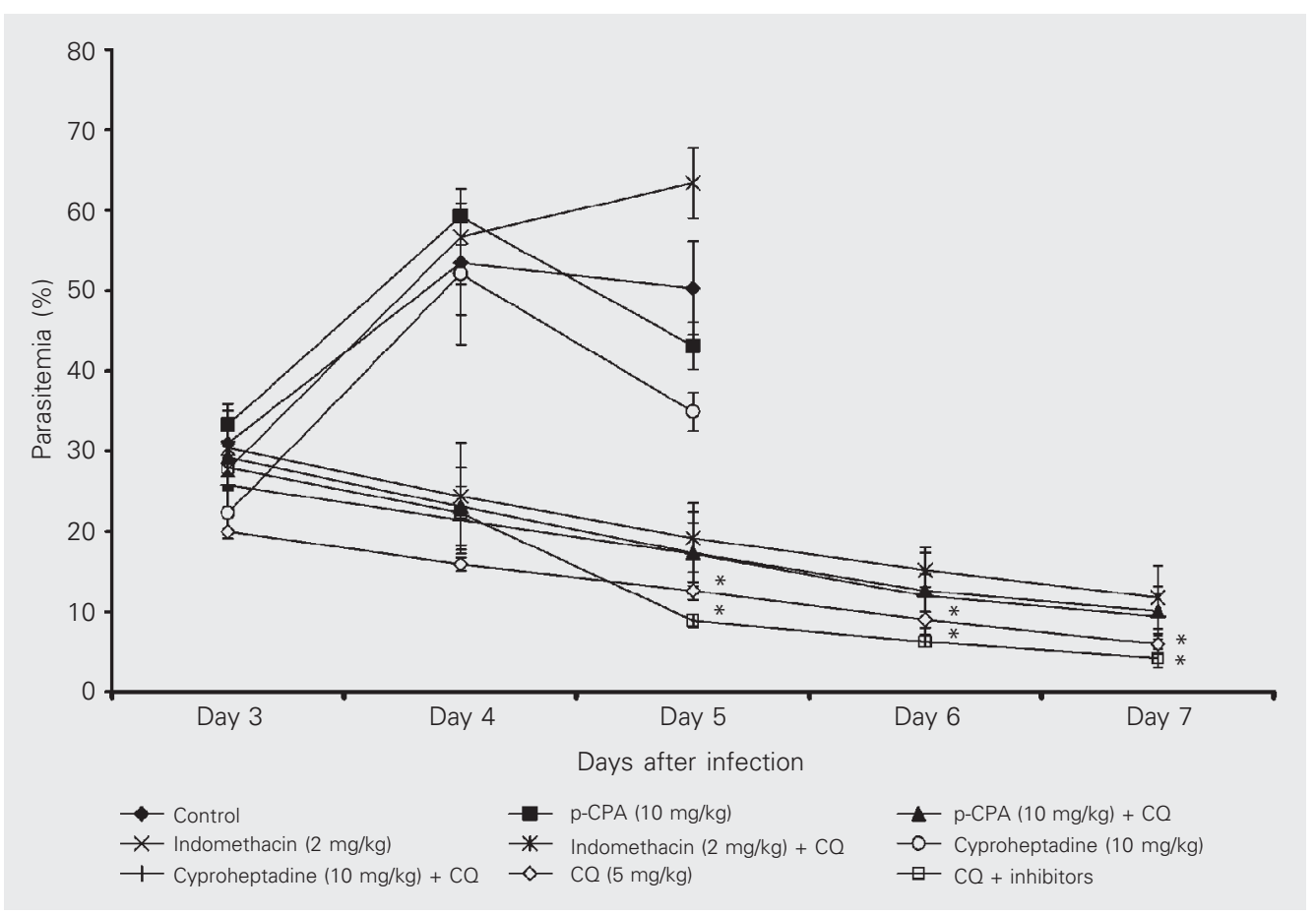

Figure 1. Curative treatment: parasitemia of Plasmodium yoelii nigeriensis-infected malarial mice treated with autacoid inhibitors, an antagonist, chloroquine and their combinations. Data are reported as means \pm SEM for 5 mice in each group. $\mathrm{CQ}=$ chloroquine; $\mathrm{p}-\mathrm{CPA}=\mathrm{p}$ chlorophenylalanine. ${ }^{*} \mathrm{P}<0.05$ compared to control group (Student $t$-test). 


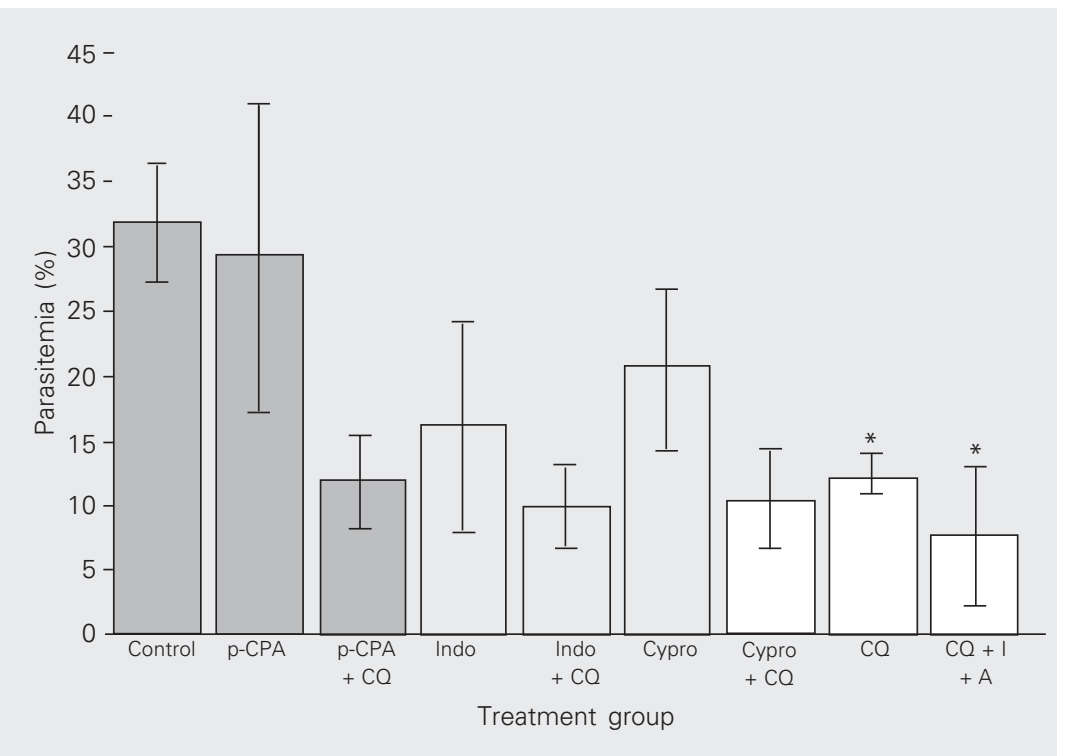

Figure 2. Prophylactic treatment: parasitemia at 3 days post-infection of Plasmodium yoelii nigeriensis-infected malarial mice treated with autacoid inhibitors ( $\mathrm{p}$-chlorophenylalanine (p-CPA, $10 \mathrm{mg} / \mathrm{kg}$ ) and indomethacin (Indo, $2 \mathrm{mg} / \mathrm{kg}$ )), the antagonist cyproheptadine (Cypro, $10 \mathrm{mg} / \mathrm{kg}$ ), chloroquine $(\mathrm{CQ}, 5 \mathrm{mg} / \mathrm{kg}$ ), their combinations $(\mathrm{p}-\mathrm{CPA}+\mathrm{CQ}$, Indo $+\mathrm{CQ}$, Cypro $+\mathrm{CQ}$, and $\mathrm{CQ}+$ inhibitors (I) + antagonist (A)), and $0.3 \mathrm{ml}$ normal saline (control). Data are reported as percent \pm SEM for $N=5$ animals in each group. ${ }^{*} \mathrm{P}<0.05$ compared to control group (Student $t$-test).

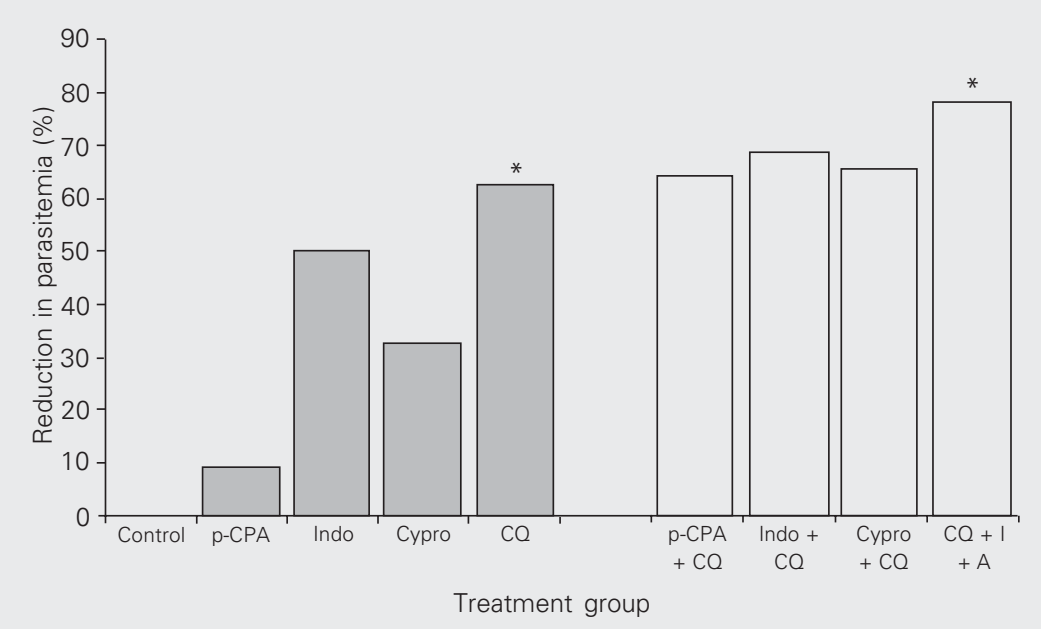

Figure 3. Reduction of parasitemia at 3 days post-infection in Plasmodium yoelii nigeriensisinfected malarial mice $(N=5)$ treated with autacoid inhibitors ( $p$-chlorophenylalanine ( $p$ CPA, $10 \mathrm{mg} / \mathrm{kg}$ ) and indomethacin (Indo, $2 \mathrm{mg} / \mathrm{kg}$ )), the antagonist cyproheptadine (Cypro, $10 \mathrm{mg} / \mathrm{kg}$ ), chloroquine $(\mathrm{CQ}, 5 \mathrm{mg} / \mathrm{kg}$ ), their combinations (p-CPA + CQ, Indo + CQ, Cypro + $\mathrm{CQ}$, and $\mathrm{CO}+$ inhibitors (I) + antagonist (A)), and $0.3 \mathrm{ml}$ normal saline (control). Data are reported as percent \pm SEM for $N=5$ animals in each group. ${ }^{*} \mathrm{P}<0.05$ compared to control group (Student $t$-test). nations on established malaria infection. p$\mathrm{CPA}$, indomethacin and cyproheptadine did not demonstrate significant anti-malarial activity in vivo in monotherapy as curative agents. p-CPA and cyproheptadine reduced parasitemia level by 43.1 and $34.9 \%$, respectively, on day 5 of curative treatment; the animals in these groups, however, did not survive the 7-day treatment period.

As prophylactics (Figures 2 and 3 ) the autacoid inhibitors $(10 \mathrm{mg} / \mathrm{kg} \mathrm{p}-\mathrm{CPA}$, and 2 $\mathrm{mg} / \mathrm{kg}$ indomethacin) and the antagonist (10 $\mathrm{mg} / \mathrm{kg}$ cyproheptadine) reduced the level of parasitemia in infected mice in monotherapy. CQ and its combination with the autacoid inhibitors and the antagonist showed significant reductions relative to control $(\mathrm{P}<$ 0.05 ; Figures 2 and 3 ). In both treatment methods, CQ and its single combination with autacoid inhibitors and the antagonist exhibited a marked immediate reduction in parasitemia level in the curative regimen, with the effect being more than that of CQ alone in both prophylactic and curative treatments (Figures 1, 2 and 3). The mean percent parasitemia level within the curative treatment days showed that the suppression in parasitemia level observed for CQ + P-CPA, CQ + indomethacin and $\mathrm{CQ}+$ cyproheptadine was similar to the anti-malaria effects of $\mathrm{CQ}$ alone. However, in the prophylactic treatment the agents in single combination with CQ maintained an average $78.1 \%$ reduction in parasitemia level compared with a mean reduction of $62.5 \%$ for $\mathrm{CQ}$ alone (Figures 2 and 3), with both values being statistically significant.

\section{Discussion}

Malaria infection has been shown to cause an inflammatory reaction leading to the release of various chemical mediators such as histamine, 5-HT, bradykinins and prostaglandins (4-6). Thus, in the present study we examined the possible effects of autacoid inhibitors and antagonists on malaria infec- 
tion to determine the possibility of co-administering these agents with common standard antimalarials for effective malaria therapy.

The curative experiments (Figure 1) indicate that the autacoid inhibitors and the antagonist p-CPA (a serotonin inhibitor), indomethacin (a prostaglandin inhibitor) cyproheptadine (a 5-HT, bradykinin and histamine antagonist) used had no curative effect on an established malaria infection, perhaps because they lack radical killing or suppressant activity on the parasites in monotherapy or on the various pharmacologically active substances produced by the parasite that enhance tissue damage and hamper the immune response (13). Evidence suggests that acute malaria infection induces a temporal reduction of the immune response via autacoids $(8,13)$; for example, during infection with a plasmodium parasite, circulating $\mathrm{T}$ cells are reduced in number, accompanied by a decrease in lymphoproliferative response and cytokine release by peripheral blood mononuclear cells when stimulated by malaria antigens (7). This effect has been reversed in vitro by the use of indomethacin, thus implicating the occurrence of prostaglandin secreted by activated macrophages. The baseline parasitemia levels in the group treated with CQ + autacoid inhibitors + antagonist were higher than in the group treated with CQ alone (Figure 1). The former group, however, had lower parasitemia levels after 4 days of curative treatment, indicating that inhibiting selected autacoids released during malaria infection may enhance the efficacy of clinical suppressant or radical cure drugs. The exact mechanism by which this is achieved is not fully understood although recent research suggests the inhibition of haem polymerase as the mechanism of action for the enhanced anti-malarial activity of the combination of CQ and cyproheptadine (8).
The prophylactic treatment (Figures 2 and 3 ) of the infected mice further indicates that a number of the pathological manifestations of malaria are mediated via autacoids since the use of indomethacin, p-CPA and cyproheptadine before infection reduced parasitemia level after infection and prolonged the survival period. The reduction in parasitemia levels were significant $(\mathrm{P}<0.05)$ only for the CQ and CQ + combination groups and probably contributed to the inhibition of the mediators responsible for the immunosuppressant effect of acute malaria $(7,13)$.

Tricyclic anti-histaminic agents have been reported to possess prophylactic activity since treatment with $5 \mathrm{mg} / \mathrm{kg}$ ketotifen and $50 \mathrm{mg} /$ $\mathrm{kg}$ terfenadine completely prevented the establishment of infection in mice inoculated with the sporozoites of $P$. yoelii nigeriensis (9). Also, the combination of $15 \mathrm{mg} / \mathrm{kg}$ cyproheptadine and CQ in suppressive treatments of malarial mice improved anti-malarial activity compared to treatment with either drug alone (8). The results, however, indicate that p-CPA, indomethacin, and cyproheptadine did not completely prevent $\mathrm{RBC}$ invasion by the malaria parasites but show that these drugs are effective as prophylactics when compared to CQ and enhance its prophylactic and curative properties.

The biological activity of malaria parasites in the host is governed by many conditions which need to be understood in order to develop a suitable chemotherapeutic agent and regimen for their control. The present study reports that the selective inhibition of local hormones implicated in the pathological manifestations of malaria infection by autacoid inhibitors and antagonist is a possible means to reduce infection severity and associated tissue damage and for enhancing the efficacy of available anti-malarials. 


\section{References}

1. World Health Organization (2000). Severe Falciparum malaria (severe complicated malaria - 3rd edn.). Transactions of the Royal Society of Tropical Medicine and Hygiene, 94: S1/1-S1/11 and S1/ 34-S1/35.

2. Killick-Kendrick R (1978). Taxonomy, zoography and evolution. In: Killick-Kendrick R \& Peters W (Editors), Rodents Malaria. Academic Press, London, UK, 1-52.

3. Landau I \& Chabaud A (1994). Plasmodium species infecting Thamnomys rutilans: A zoological study. Advances in Parasitology, 33: $50-90$.

4. Onabanjo AO \& Maegraith BG (1970). Inflammatory changes in small blood vessels induced by kallikrein in Macaca mulatta infected with Plasmodium knowlesi. Annals of Tropical Medicine and Parasitology, 64: 227-236.

5. Maegraith BG \& Onabanjo AO (1970). The effects of histamine in malaria. British Journal of Pharmacology, 39: 755-764.

6. Cordeiro RSB, Cunha FQ, Assreay Filho J, Flores CA, Vasconcelos HN \& Martins MA (1983). Plasmodium berghei: Physiopathology changes during infection in mice. Annals of Tropical Medicine and Parasitology, 77: 455-465.

7. Riley EM (1988). Cellular and humoral response to Plasmodium falciparum antigen in Gambian children during and after an attack of acute Plasmodium falciparum malaria. Clinical and Experimental Immunology, 73: 17-22.

8. Agrawal R, Tripathi R, Tekwani BL, Jain SK, Dutta GP \& Shukla OP (2002). Haem polymerase as a novel target of antimalarial action of cyproheptadine. Biochemical Pharmacology, 64: 1399-1406.

9. Singh N \& Puri SK (1998). Causal prophylactic activity of antihistaminic agents against Plasmodium yoelii nigeriensis infection in Swiss mice. Acta Tropica, 69: 255-260

10. Ryley JF \& Peters W (1970). The antimalaria activitiy of some quinoline esters. American Journal of Tropical Medicine and Parasitology, 84: 209

11. Peters W (1965). Drug resistance in Plasmodium berghei. Vinke and Lips 1948. I. Chloroquine resistance. Experimetal Parasitology, 17: 80-89

12. Gadiner WP \& Gettinby G (1998). Experimental Design Techniques in Statistical Practical Software Base Approach. 1st edn. Horwood Publishing, Chichester, UK, 18-26.

13. Kubata KB, Eguchi N, Urade $Y$, Yamashita K, Mitamura T, Tai K \& Horii $T$ (1998). Plasmodium falciparum produces prostaglandins that are pyrogenic, somnogenic and immunosuppressive substances in humans. Journal of Experimental Medicine, 188: 1197-1202. 